AGRICULTURE AND BIOLOGY JOURNAL OF NORTH AMERICA

ISSN Print: 2151-7517, ISSN Online: 2151-7525 , doi:10.5251/abjna.2011.2.12.1416.1426

(C) 2011, ScienceHuß, http://www.scihub.org/ABJNA

\title{
Distribution of injected pesticides in date palm trees
}

\author{
Adnan I. Al Samarrie* and Abula Abo Akela \\ *Specialist of Toxicology, Abu Dhabi Food Control Authority, \\ Agricultural Sector Abu Dhabi, UAE \\ adnan.alsamarrie@adfca.ae, adnan_ibraham@yahoo.com \\ Abu Dhabi Food Control Authority, Research and Development Sector
}

\begin{abstract}
The insecticides Rogodial (dimethoate + phenthoate), Actellic (primiphos-methyl), Salut \{(chlorpyrifos-ethyl) + dimethoate\}, Reldan (chlorpyrifos-methyl) and Karate (lambda-cyhalothrin) translocation and movement in date palm trees were evaluated. It found that the systemic and non-systemic insecticides moved out of injection pores. The injected pesticides detected 10 Days post Injection (DPI) at one meter above the injection point in the same and opposite side of injection pore. The five individual injected pesticides distributed downward at concentrations of $0.01,0.011,0.009,0.011$ and $0.009 \mathrm{mg} / \mathrm{kg}$ of actellic, salut, karate, reldan and rogodial respectively. At $20 \mathrm{DPI}$ all studied pesticides were detected in the pith at $2 \mathrm{~m}$ above the injection side either individually or mixture injected pesticides, Similarly, the pesticides were found to be distributed downward at concentrations of $0.042,0.036,0.005,0.019$ and $0.025 \mathrm{mg} / \mathrm{kg}$ of actellic, salut, karate, reldan and rogodial respectively. The residues of four insecticides detected in dates $100 \mathrm{DPI}$, the insecticide residue levels of karate in the dates were $0.0034 \& 0.019$ of mixed and individual injected pesticides respectively which were the highest levels at 100DPI.
\end{abstract}

Keywords: Date palm, pesticides translocation, trunk injection, residue in dates

\section{INTRODUCTION}

Date palm insects' infestation could cause a dramatic damage to date palm plants. Several chemical pest control protocols recommended in UAE whereby several pesticides have shown acceptable results for some extend, the most applied pesticides are chlorpyrifos- methyl, dimethoate, lambdacyhalothrin, thiomethoxam and primiphos-methyl etc. Many pesticide application methods demonstrated namely, trunk injection, trunk spraying and drainage. The pesticides trunk spray and phostoxine tablets are widely practiced in UAE to control red palm weevil, recently the attitude started to divers to the trunk injection technique. The mentioned practice has been applied worldwide long time ago; meanwhile, the Arab scientists used this application to inject different chemicals in fruit trunks for impairing curative and perfumes or colours to flowers, in early $20^{\text {th }}$ century the first application of the trunk injection carried out Roach 1939.

The pesticides trunk injection technique in pest control and tree fertilization shows many advantages such as; minimizing the used chemicals, environmental safety, protection of non target organisms, water saving and reduction in the labour cost.

The pesticides can reach the plant sap either by root up take, penetration through leaves and stem or directly by injection into trunk. The injection of the pesticides in the trunk can carried out by applying low pressure or pressurized method. Recently, the trunk injection method, widely applied over the world particularly in palm oil trees and tree care industry. The main constrain facing the trunk injection is the recovery of wounds that did by drilling holes through trunks. According to Smitley 2011, he stated that these holes cause no harm to plant and they can recover.

The pesticides translocation and/or distribution in plant tissues are manipulated by the pesticide physical properties such as solubility partitioning and polarity as well as, the appropriate application position.

The pesticides distribution in the tree parts investigated by few workers, as Sanchez and Escobar 2004 which investigated rubidium chloride solution translocation in different coniferous and angiosperms plants and they studied the impact of 
Agric. Biol. J. N. Am., 2011, 2(12): 1416-1426

the depth of the injection holes and diameters on the translocated volume and the speed of translocation. The translocation speed and distribution of thiamethoxam (actara) in the pith of the date palm monitored by Al Sammariae et.al 2006, while Harrell 2006 investigated the imidacloprid translocation in green ash trees.

The present work investigated the translocation and distribution behaviour post injection of five insecticides in date palm tissue and at different maturation stages of date fruits, all those pesticides were recommend for controlling red palm weevil in UAE.

The aim of this work is to investigate the distribution of some pesticides in date palm trunk and fruits at different intervals of time. Moreover, the trials evaluated the efficiency and adequacy of one hole in date palm trunk to distribute the pesticides in the plant tissues.

\section{MATERIALS AND METHODS}

The trials accomplished at the Al Kuatat agricultural research station/ Al Ain, UAE 2010-2011.

Injection apparatus: The low pressure injection units were locally adapted as in (fig 1) by using 1.5 I plastic bottles which was connected to canola apparatus by rubber tube, the syringe was inserted into the hole and the flow rate was adjusted to prevent over flow out of the injection pore. The bottles fixed on the trunk one meter above the injection pore.

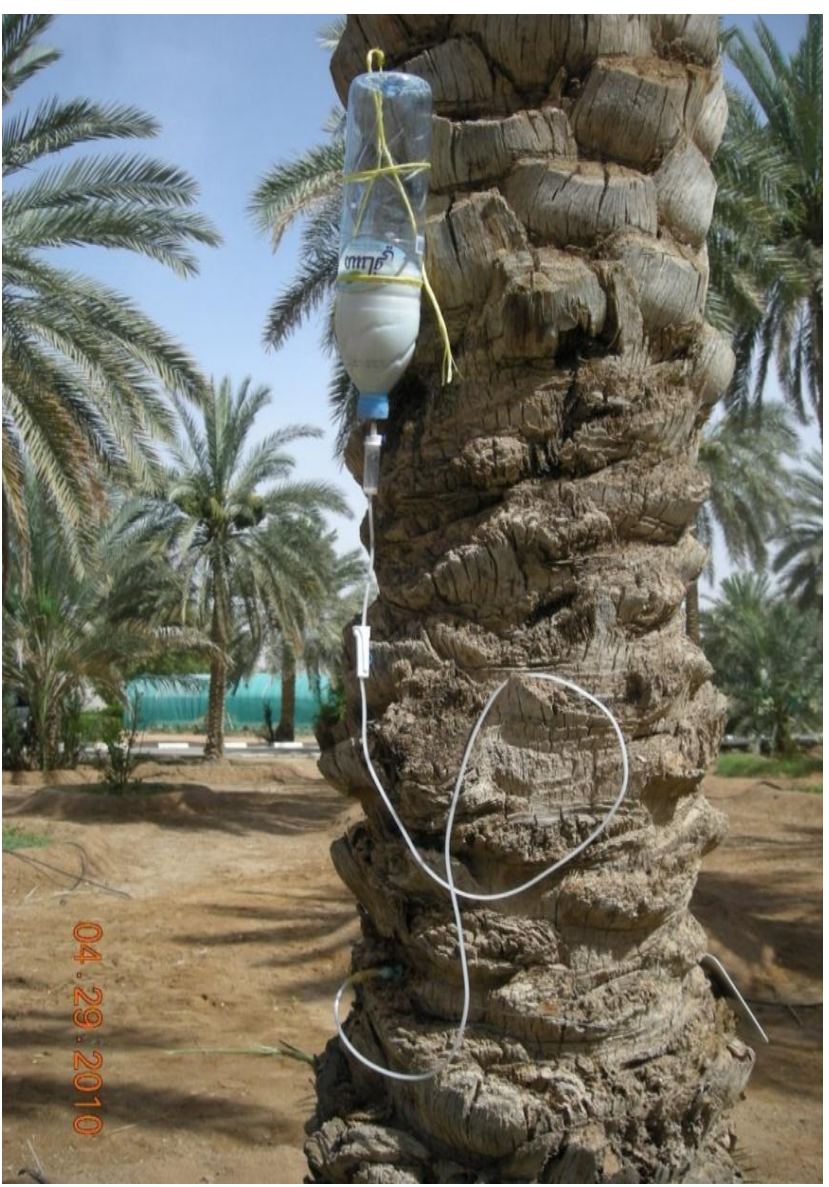

Fig 1: The injection apparatus

The translocation, distribution and residues in dates of five different insecticides (nominated by Abu Dhabi agriculture sector) to control the red palm weevil were investigated post injection, the injected insecticide volumes in the trunk as shown in following table.

\begin{tabular}{|l|l|l|l|}
\hline Insecticide & Mixing rate & $\begin{array}{l}\text { Injected formulated } \\
\text { volume ml/palm }\end{array}$ & $\mathrm{ml}$ a.i./plant \\
\hline $\begin{array}{l}\text { Rogodial } 50 \text { EC (dimethoate 11\% and phenthoate } \\
41 \%)\end{array}$ & $2 \mathrm{ml} / \mathrm{l}$ & $3 \mathrm{ml}$ & 1.5 \\
\hline Actellic 50EC (primiphos methyl) & $1.5 \mathrm{ml} / \mathrm{l}$ & 2.5 & 1.25 \\
\hline $\begin{array}{l}\text { Salut 50EC (chlorpyrifos ethyl 278g and dimethoate } \\
222 \mathrm{~g}\end{array}$ & $1.75 \mathrm{ml} / \mathrm{l}$ & 2.5 & 1.25 \\
\hline Reldan 40EC (chlorpyrifos methyl) & $1.25 \mathrm{ml} / \mathrm{l}$ & 2 & 0.8 \\
\hline Karate 10CS (lambda-cyhalothrin) & $1 \mathrm{ml} / \mathrm{l}$ & 1.5 & 0.15 \\
\hline Mixture of all insecticides at same mixing rate & & & \\
\hline
\end{tabular}


Injection holes: The injection pores drilled within dimensions of $(2.5 \times 12) \mathrm{cm}$ with a slope of 45 degree situated at 1.5 meter above the ground. One pore per date palm drilled, where the canola fitted in the pore by a stopper.

Date Palm: Eighteen date palms of Jash variety with nearly similar height of $6.5-7.5 \mathrm{~m}$ in the age of 19 years were involved in the trials; the treatment consisted of three replicates. The plants irrigated with approximately of $317 \mathrm{l} /$ plant each two days.

Sampling: The sampling pores drilled 1 meter above the injection pore at the same and opposite of the injection pore and another hole at 2 meters at the same injection side. The pith samples drilled out of the date palm trunk at different intervals post injection using electrical drill, while date fruit samples collected at different growth stages. All the samples putted in sample bags then stored in deep freezer until analysis done. Pith samples collected as flowing:

10 days post injection (DPI), one meter above injection pore at both same and opposite injection sides.

$20 \mathrm{DPI}$, two meters above injection pore of same injection side.

$30 \mathrm{DPI}$, one meter below injection pore of same injection side.

Khlal samples collected at $30 \mathrm{DPI}$.

Ritab samples collected at $60 \mathrm{DPI}$.

Date samples collected at $100 \mathrm{DPI}$.

Extraction and detection: All the analysis carried out in ADFCA laboratories/ pesticide residue unit. The extraction and detection fallowed the ADFCA accredited multi residue method No. LAD-DPMCHPR-04, Multi residue method 2010.

The detection and confirmation of the injected insecticides based on the active ingredient of the formulations; whereby rogodial detection based on the dimethoate while, salut measurements based on the chlorpyrifos- ethyl and reldan calculated depending on chlorpyrifos - methyl, so that the concentration of rogodial in mixture trials is a collective value of dimethoate of salute and rogodial itself.

\section{RESULTS}

The distribution and translocation of pesticides in date palm trees did not investigate deeply despite the few published articles that are covering the pesticide residues in date fruits.
The current work shows that, all candidate pesticides moved out of the injection pore irrelevant to their systemic behaviour.

The results revealed that the pesticides (Reldan, Salut and Karate either individual or mixture of pesticides injected) distributed through the date palm trunk. The pesticides detected in pith at one meter above the injection pore at 10 DPA, in the same and the opposite sides of injection pore, the detected concentrations in pith of individual injection of reldan, salut and karate at the same injection side, were $0.029,0.008$ and $0.002 \mathrm{mg} / \mathrm{kg}$ respectively. On other hand, the concentrations of mixture injection were $0.015,0.005$ and $0.012 \mathrm{mg} / \mathrm{kg}$ at same manner. Moreover, same three insecticides were detected at opposite side of injection either as individual or mixture injected pesticide; the concentrations in pith were $0.007,0.008$ and 0.019 of mixture injection and $0.01,0.003$ and $0.013 \mathrm{mg} / \mathrm{kg}$ of individual injection respectively, Fig 2 a \& b.

At $20 \mathrm{DPI}$ all studied pesticides were detected in the pith at $2 m$ above the injection side either individually or mixture injected pesticides, (fig 3 a \& b). Similarly, the five individual injected pesticides were found to be distributed downward at concentrations of 0.01 , $0.011,0.009,0.011$ and $0.009 \mathrm{mg} / \mathrm{kg}$ of actellic, salut, karate, reldan and rogodial respectively as shown in fig 4-a \& 4-b

The current work indicated that the systemic and non-systemic injected pesticides detected in low concentrations in khilal, retab and dates. Fig. 5 - a \& b, $6-a \& b$ and $7-a \& b$; the residue levels of insecticide karate in the dates at 100DPI were 0.0034 \& 0.019 of mixed and individual injected pesticide, which were the highest levels fig 7- a \& b.

\section{DISCUSSION}

The distribution of the pesticides in trunk sap facilitated by existing of large vascular bundles tubes over whole trunk of date palm. The non-systemic pesticide moved due to diffusion that occurs when a pesticide travels from an area of high concentration to an area of low concentration by way or random molecular movement; this movement is much slower than mass flow, which transports the pesticide by flow of water, Martin \& Peter 1992, whereas the movement of the pesticides accelerated by the mass water flow and diffusion in the trunk. Kramer and Kozlowiski 1960, they pointed out that, the sap moves very rapidly in tree stem, it reached 25-60 meter per hour in the xylem of oak and 1-6 meter in maples and beech xylem, on other hand $\mathrm{Al}$ 
Sammariae, et.al. 2006 found that actara moved at a rate of $2.8 \mathrm{~m} / \mathrm{hrs}$ in date palm trunk.

In point of downward movement of the pesticides it is mainly related to diffusion and downward behaviour of the pesticides but finally the pesticides will station in plant tissues depending on the partition coefficient.

According to the results it seems that there is no need to drill more than one hole per palm trunk to introduce the pesticides inside the trunk as long as the pesticides moved out of injection site and distributed fairly in date palm tissues. The rapid pesticides distribution in date palm trunk relate to the distribution of xylem and phloem bundles in trunk.

The distribution of the injected pesticides in the date palm trunk sap and pith is a substantial factor that governs the success of trunk pests control as long as exists of adequate lethal concentrations. These findings agreed with the results of Al Jboory et.al 2001, where they found that thiamethoxam moved in date palm trunk pith at 4.5 meter above the injection pore, and the current work consent with Harrell 2006 that he found that imidacloprid detected of different concentrations in the sap of green ash trees at $0,3,7,30,60$ and 90 days.

In the case of pesticides mixture injection, the residues of rogodial and salut based on the dimethoate and chlorpyrifos-ethyl detection respectively, while reldan residues measured according to chlorpyrifos-methyl.

No Maximum Residue Limit (MRLs) for pesticides in dates determined by CODEX till now except the acaricide "hexythiazx", while the EU MRLs for dimethoate, chlorpyrifos-ethyl, chlorpyrifos-methyl, primiphos-methyl and lambdacyhalothrin in dates were based on the Lower of Analytical Determination (LOD) because this level of pesticide residues used normally for banned or highly restricted pesticides. The establishment of local MRLs for the pesticides in dates is quite essential for the food safety requirements.

Few works carried out on pesticide residues in dates. Al-Samarriae et.al 1989, used fenitrothion, chlorpyrifos and primiphos-methyl to control the lesser date moth by mixing the pesticide with pollen grains at a concentration of $5 \mathrm{mg} / \mathrm{kg}$, it was found that the residues in dates were at negligible levels at harvest time. Respecting to pesticide residues flowing injection through 3 holes / trunk of $30 \mathrm{ml} /$ plant of a mixture 1:1commercial formulation: water of dimethoate, nogos, endosulfan and carbosulfan, the results revealed that dimethoate residue was of 0.14 $\mathrm{mg} / \mathrm{kg}$ at 60 days post injection, A.J. Khan, et.al.; this high residues in dates of Khan's result could relate to the high initial injected doses. In a market survey for pesticide residues in dates of Riyadh city markets, the results indicated the persistence of several insecticides, fungicides, herbicides and chlorinated hydrocarbon pesticides and the residues were below and above MRLs whereas, chlorpyrifos was found to be the highest residual detected pesticide $\mathrm{H}$. M. Al Saeid and S.A. Al-Dosari. 2010, the authors detected different pesticide groups, many of these pesticides could be resulted of environmental pollution rather than of pest control programs.

The calculated residues in the current work were well below the EU values, while, the CODEX MRLs of chlorpyrifos ethyl, chlorpyrifos methyl, cyhalothrin (including lambdacyhalothrin) and dimethoate in dried grape were $0.1,0.1,0.3$ and $1.00 \mathrm{mg} / \mathrm{kg}$ respectively, by comparing Codex values with the calculated residues in dates indicated that the residues in khilal, retab and dates of the evaluated pesticides it was quite below Codex values and ranged from not detected to $0.019 \mathrm{mg} / \mathrm{kg}$. Post individual insecticide injection trials the residues of karate in khilal, retab and dates were $0.004,0.0023$ and 0.019 respectively, whereas the residues of rogodial were $0.004,0.0017$ and $0.0023 \mathrm{mg} / \mathrm{kg}$ at same manner, fig $5-a \& b, 6-a \& b$ and $7-a \& b$.

In the current work, the low pesticide residues detected in the dates revealed to the use of the Abu Dhabi agricultural sector protocol of chemical control of date palm trunk weevils which recommended low pesticide doses. 
Agric. Biol. J. N. Am., 2011, 2(12): 1416-1426

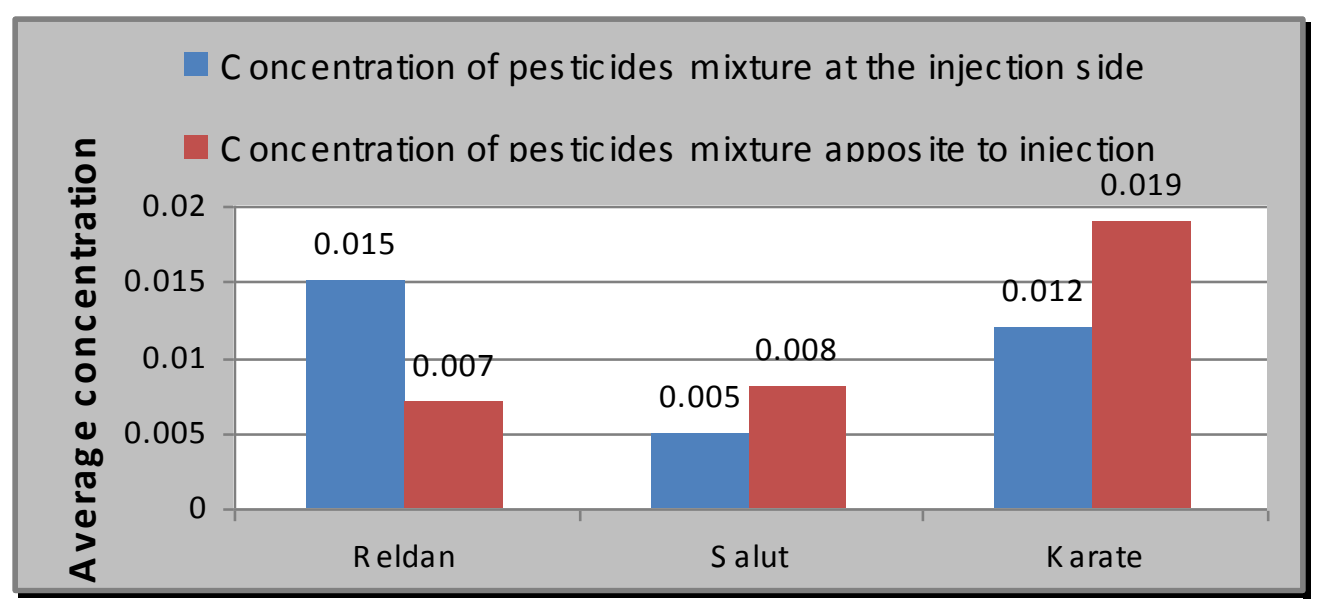

Fig. 2-a: Showing average concentrations of single injected pesticide at injection side and opposite to it, after 10 days of injection at $1 \mathrm{~m}$ above injection pore.

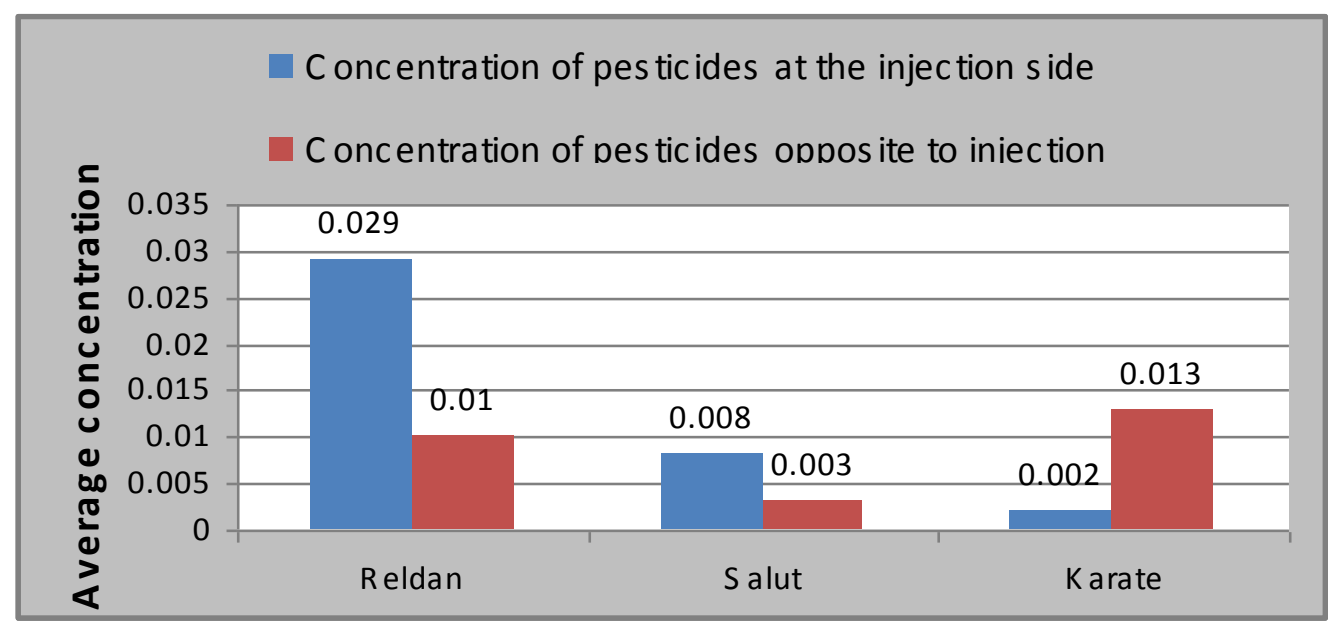

Fig 2-b: Showing; average concentrations of pesticides mixture injection, at injection side and opposite to it, after 10 days of injection at $1 \mathrm{~m}$ above the injection point. 
Agric. Biol. J. N. Am., 2011, 2(12): 1416-1426

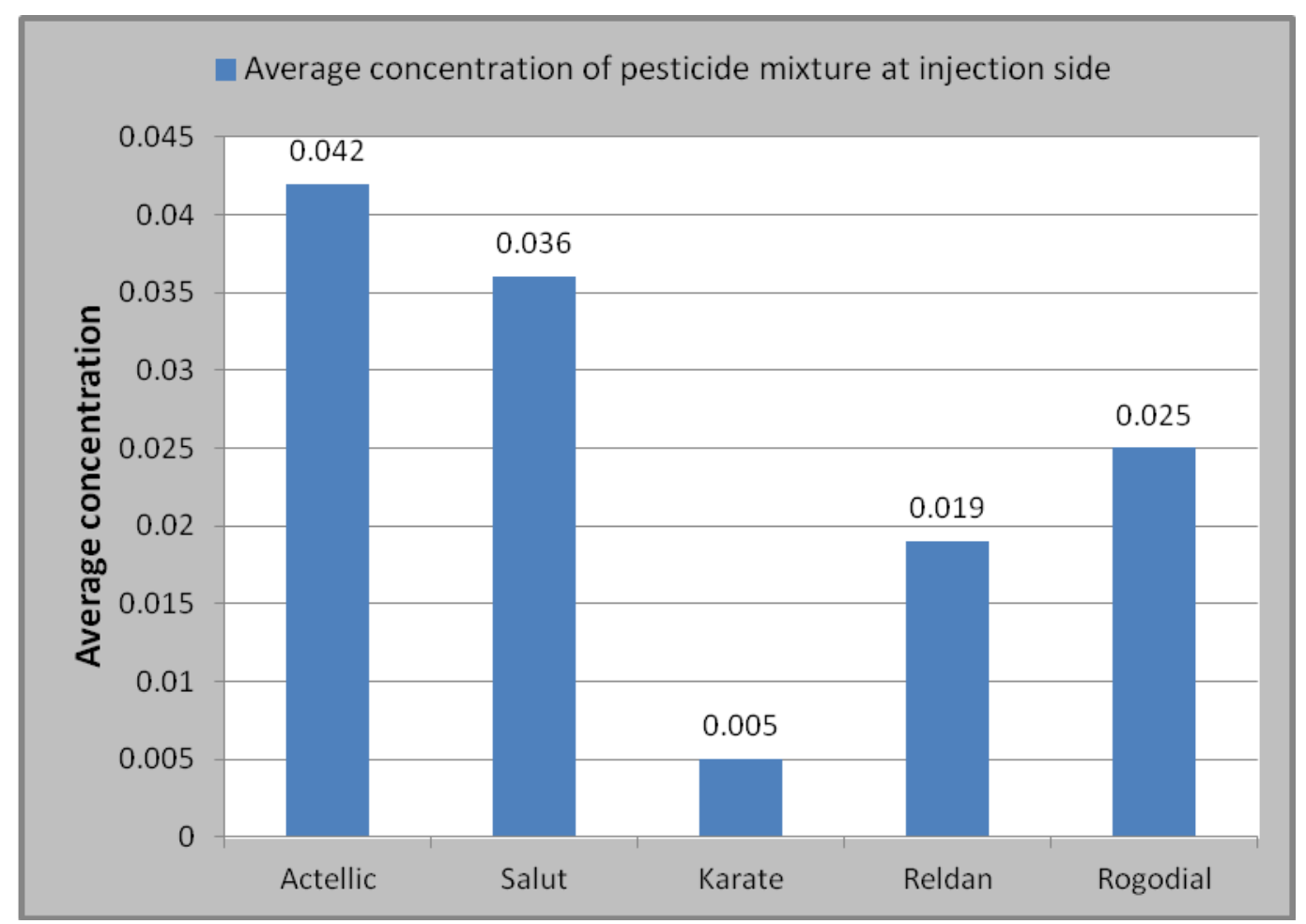

Fig 3- a: Showing average concentrations of pesticide mixture in pith of the injection side, after 20 days of injection at $2 \mathrm{~m}$ above injection point.

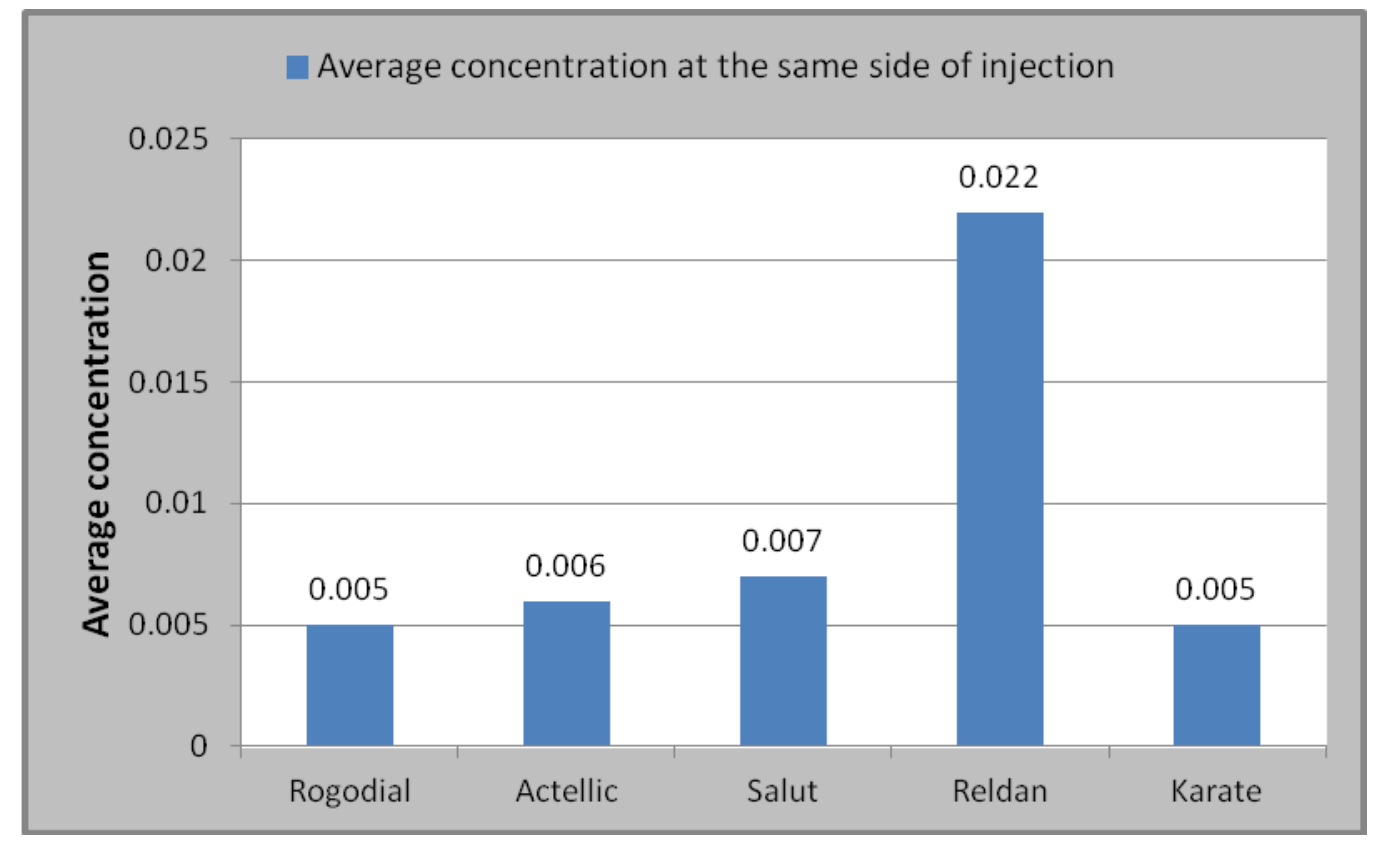

Fig 3-b: Showing average concentration of single pesticide in the pith of the trunk after 20 days of injection, at 2 $\mathrm{m}$ above injection point. 
Agric. Biol. J. N. Am., 2011, 2(12): 1416-1426

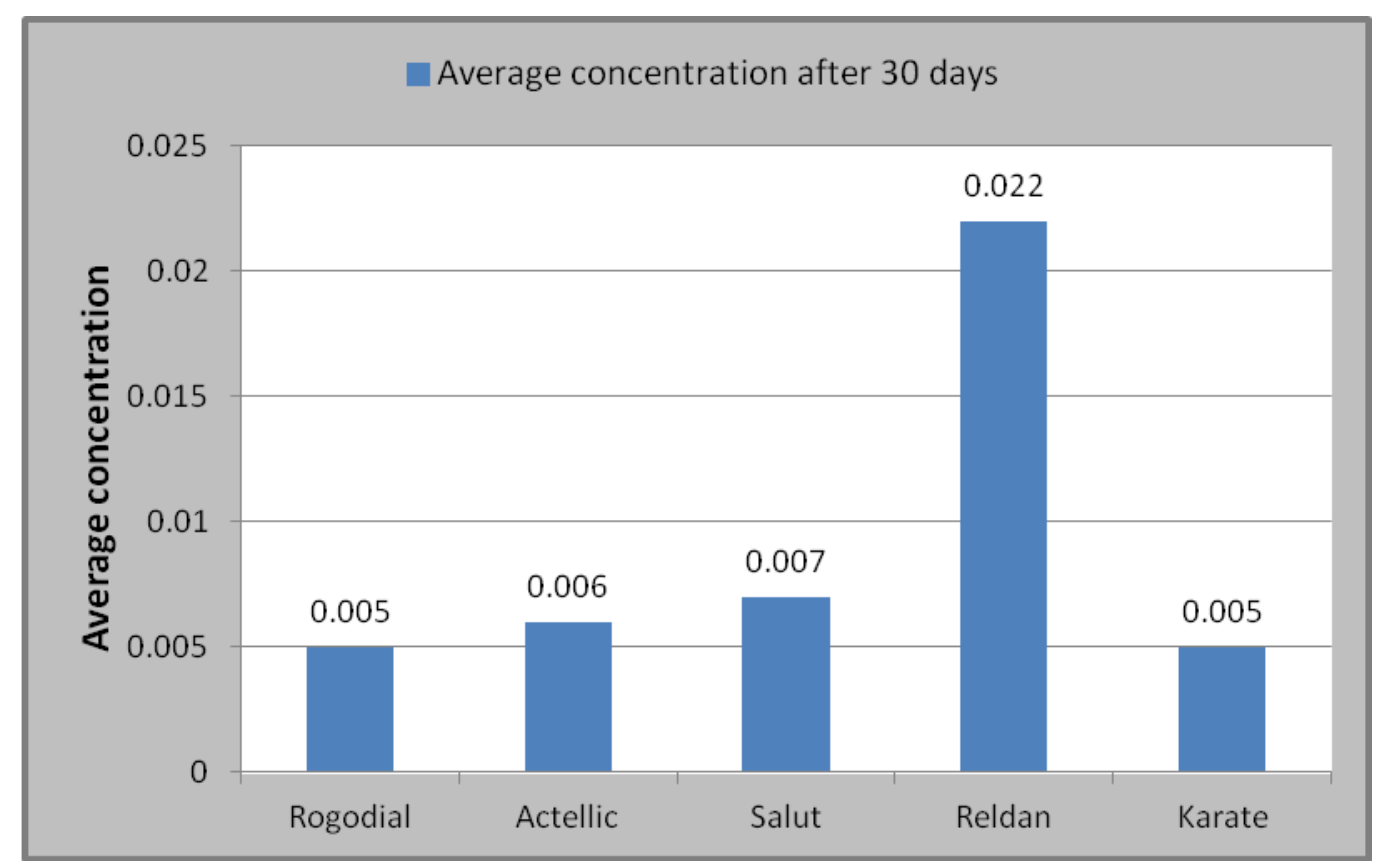

Fig 4- a: Showing average concentration of pesticides mixture in pith after 30 days post injection one meter below the injection site.

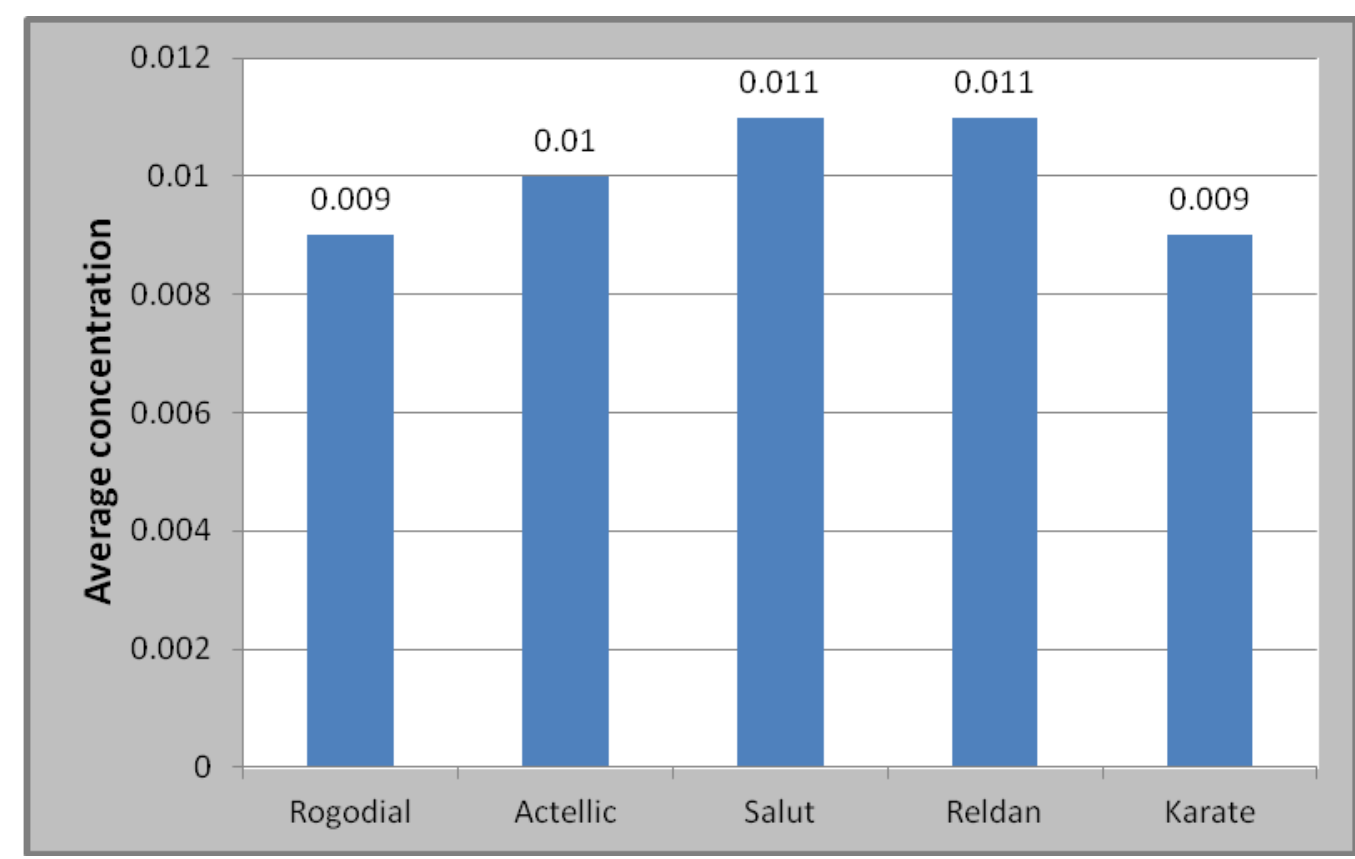

Fig 4- $b$ : The average concentrations of single pesticide injected after 30 days post injection one meter below the injection site. 
Agric. Biol. J. N. Am., 2011, 2(12): 1416-1426

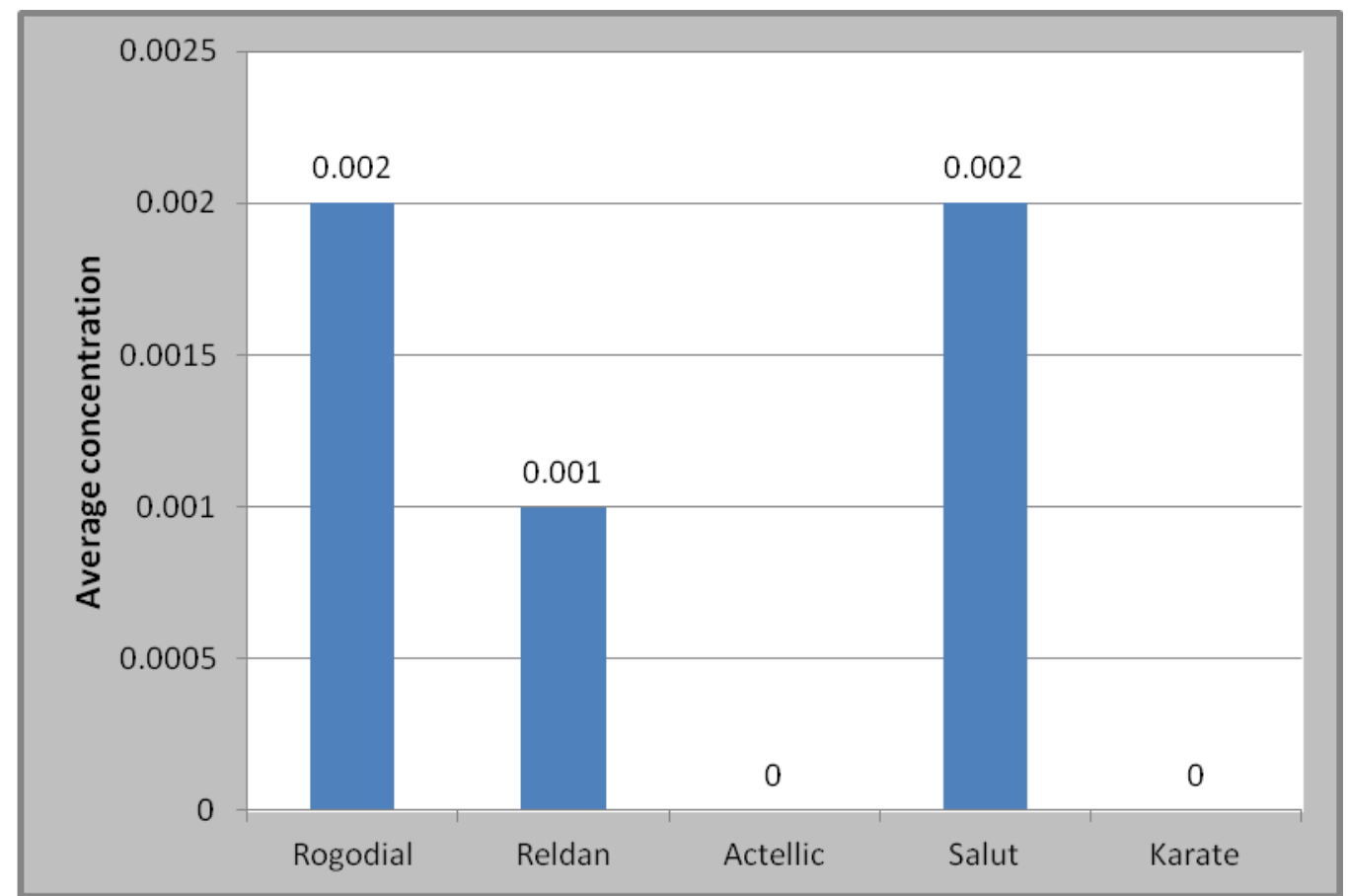

Fig 5 - a: Showing average concentration of pesticides mixture in khilal after $\mathbf{3 0}$ days of injection.

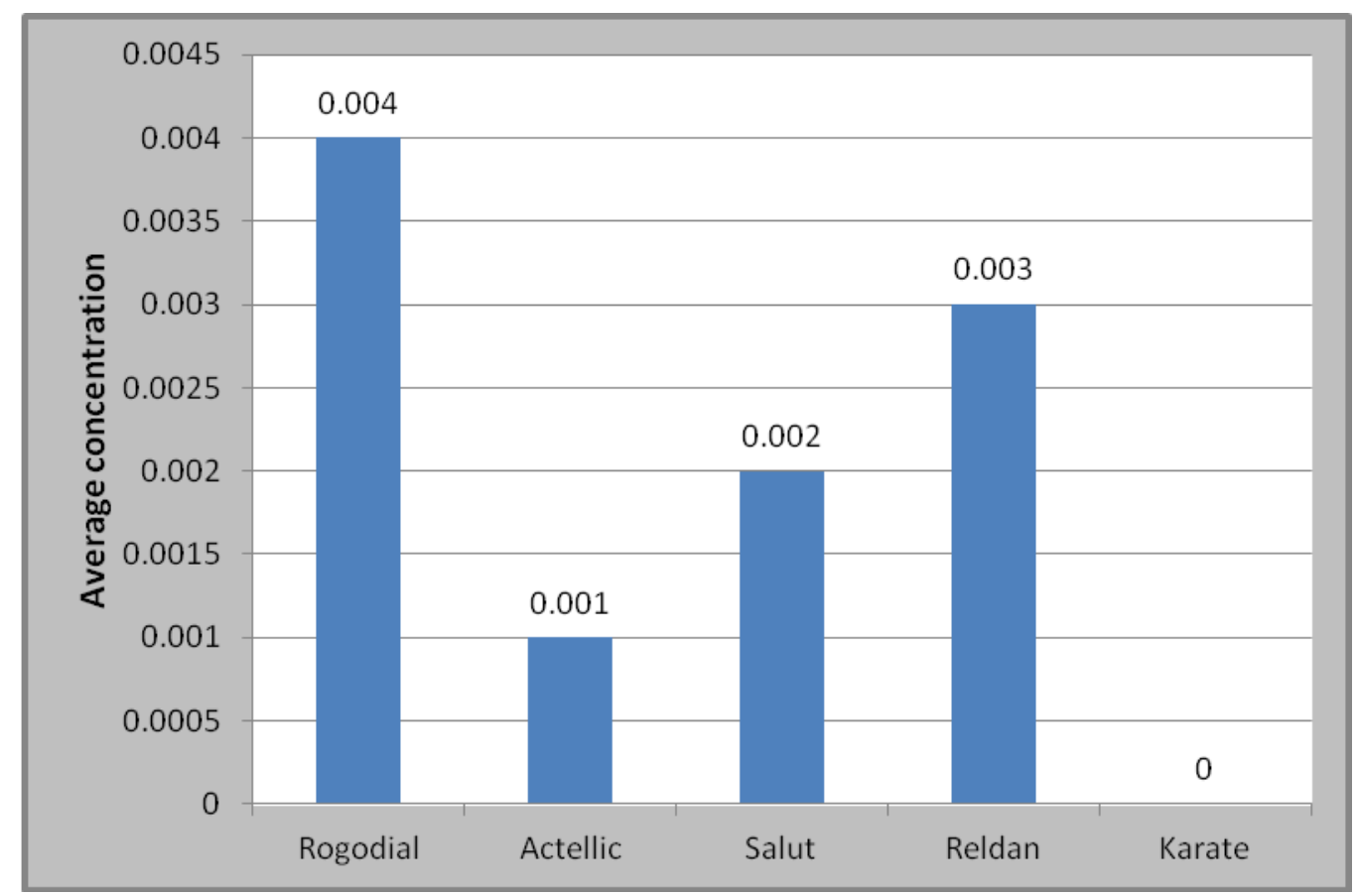

Fig 5- b: Showing average concentration of single pesticides in khilal after 30 days of injection. 
Agric. Biol. J. N. Am., 2011, 2(12): 1416-1426

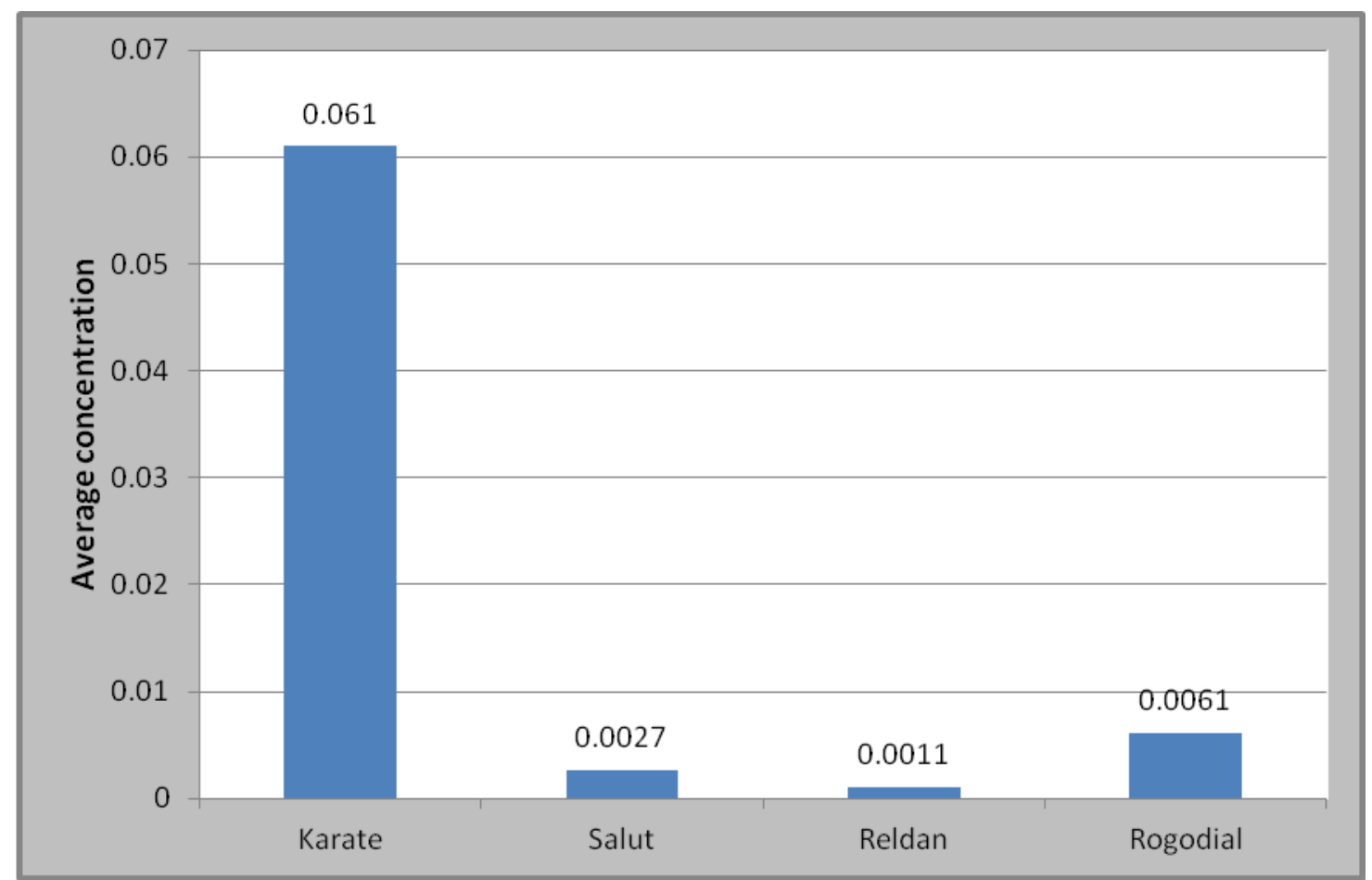

Fig 6- a: Showing average concentration of pesticide mixture in rotab after 60 days of injectio

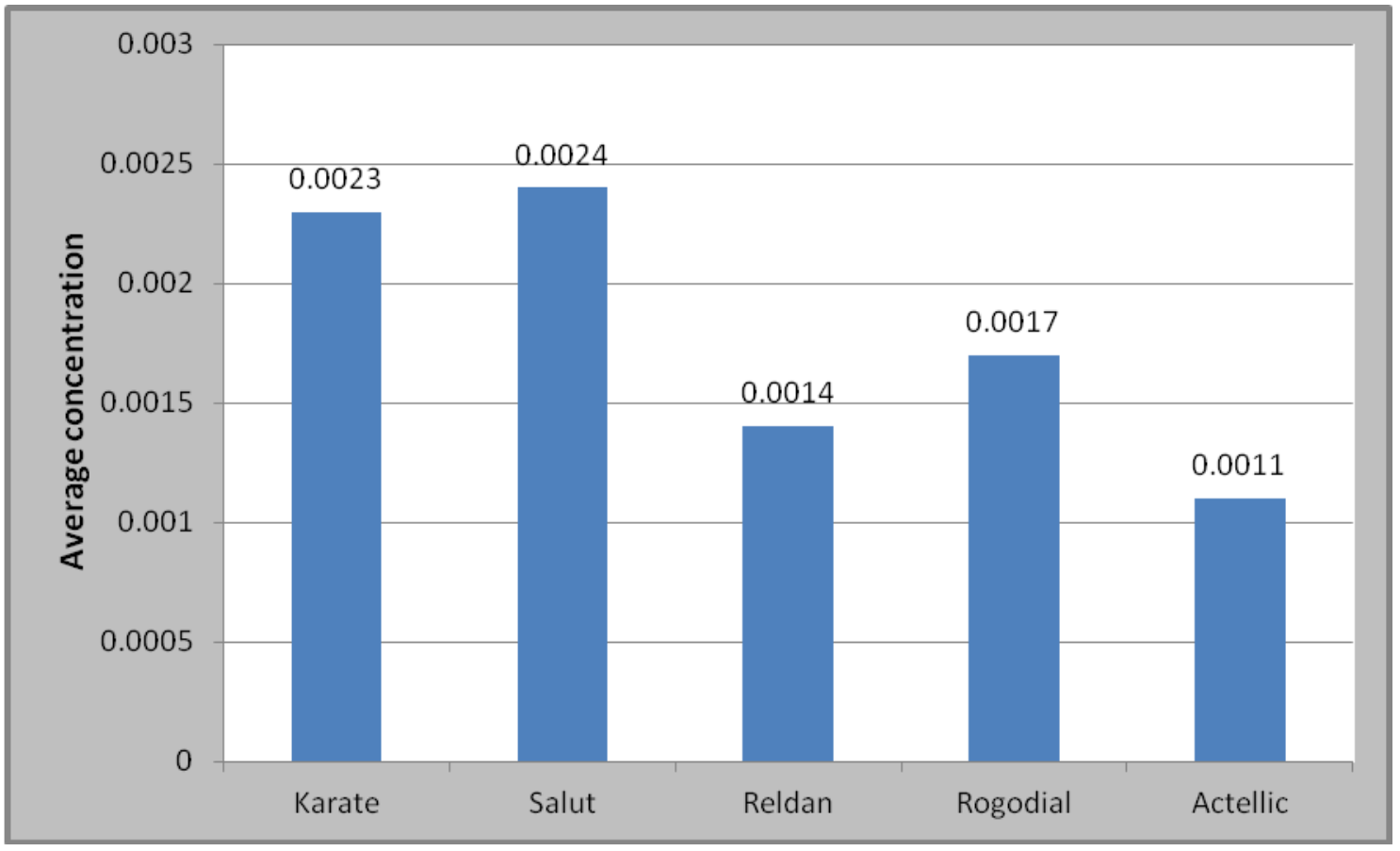

Fig 6 - b: Showing average concentration of pesticides in rotab after 60 days of injection. 
Agric. Biol. J. N. Am., 2011, 2(12): 1416-1426

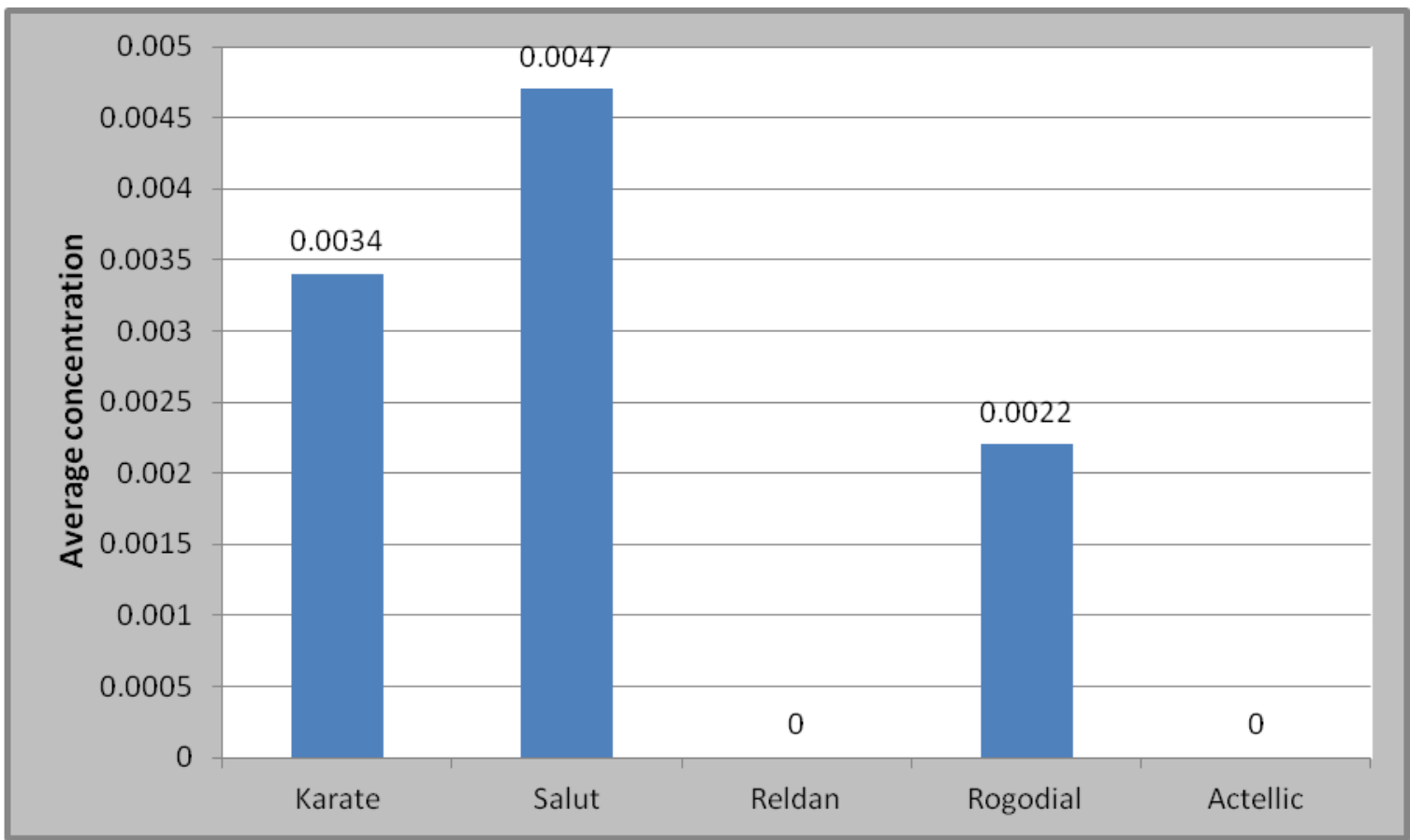

Fig 7- a: Showing average concentration of pesticides mixture in dates after 100 days.

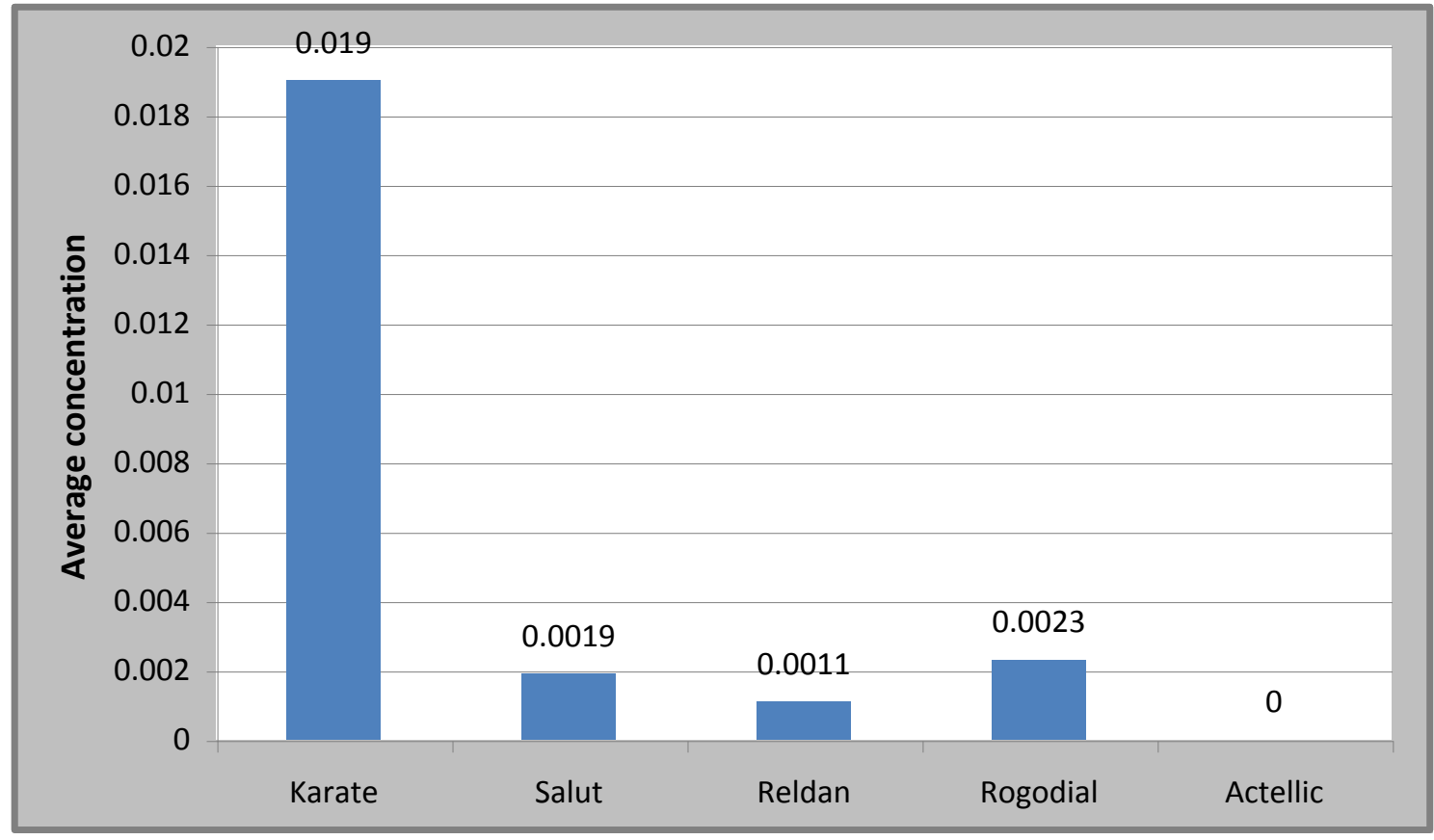

Fig 7-b: Showing average concentration of pesticides in dates after 100 days. 


\section{ACKNOWLEDGMENTS:}

The authors would like to acknowledge the pesticide residue unit of Laboratory Sector/ADFCA and agriculture extension department of AI Ain/ADFCA for their help in laboratory and field.

\section{REFERENCES}

Adnan I. Al-Samarraie ${ }^{1}$, Emad Al-Hafdh², Khloud AbdulMajed", Mabrouk A. Basumy. 1989 The chemical control of the lesser date moth, Batrachedra amydraulameyr., and residue levels of organophosphate insecticides in dates. Pesticide Science, Volume 25, Issue 3, pages 227-230,

Adnan I. Sammarie; Abduljabar A. Ali; Ausama I. Emad; Nawal H. Abas and Emad T. Yousif 2006 The translocation, distribution and concentration of thiamethoxam (actara) in date palm. Fourth date palm conference KSA, 2006

Al Jboory, I.J.; A.I. Al-Samarriae; J.F. Whaib and W.A. Ahmed, 2001 Evaluation of thiamethoxam in different application techniques to control dubas bugs. Arab J. Plant Prot. 19/2: 107-112

David Smitley, 2011 Trunk injections and changing the tree care industry. Michigan State University Extension, Dept. of Entomology, April 2011

El-Saeid M.H. and Al-Dosari S.A. 2010. Monitoring of pesticide residues in Riyadh dates by SFE, MSE, SFC and GC techniques. Arabian Journal of chemistry, 3, 179-186
Harrel Mark, 2006, Imidacloroprid concentrations in Green Ash (Fraxinus pennsylvanica) following treatments with two trunk injection methods. Arboriculture and Urban Forestry. 32 (3) May 2006

Khan, A. J. ; Azam, K.M. and Razvi, S.A. Pesticide residue analysis of date palm fruits by gas chromatography mass spectrophotometery. Univ. Qaboos, College of Agriculture, dept. Crop science. Sultanate of Oman , http://www.pubhort.org/datepalm/datepalm2/date palm2_27.pdf

Martin, J. Bukvac and Peter D. Petracek 1992. Characterizing pesticide and surfactant penetration with isolated plant cuticles. $3^{\text {rd }}$ international symposium of adjuvant for agrochemicals. University of Cambridge, UK, 3-7 Aug. 1992.

Multi- residue method for determination of pesticide residues in dates Document No: LAD-DPM-CHPR-04, Issue no: 01, Issue Date: 25.05.2010, Page: 1426 of 11. Pesticide Residues Manuel, Last printed: 8/26/2012 10:38:00 AM, Abu Dhabi Food Control Authority, UAE.

Roach, W.A. 1939.Plant injection as physiological method. Ann. Bot. 3(1): 155-226

Sanchez- Zamora, M.A, and Fernandez- Escobar, R. 2004. Uptake and distribution of trunk injections in Conifers. J. of Arboriculture, 30 (2) March 2004 